\title{
'Where to now?' Understanding the landscape of health and social services for homeless women in London, Ontario, Canada
}

\author{
Amy Van Berkum \\ Western University \\ Abe Oudshoorn \\ Western University
}

Abstract
Homelessness is an ongoing social challenge effecting women in unique ways.
The purpose of this research study was to understand a network of health and
social services accessed by women experiencing homelessness, and how
individuals successfully or unsuccessfully navigated these services. Data were
collected utilizing a participatory application of the PhotoVoice method,
grounded in a critical feminist intersectional perspective. Six women with lived
experience of homelessness were recruited from a drop-in centre to participate
in the six-week project. Through photo-taking, group discussions, arts-based
dialogue, and individual interviews, themes were developed around women's
navigation of services and experiences of homelessness. A constant
comparative method of thematic analysis was utilized so that themes could
evolve iteratively and collaboratively with both the research team reflecting
independently on qualitative data, and the women reflecting collaboratively on
the data. Themes generated included: On the Margins; Feeling at Home; Mighty
Women; Safety; Creating Home; and Whenever, Wherever. It is recommended
that: 1) Communities keep developing more safe and affordable housing; 2 )
Government investments in homelessness include a general gender lens; 3)
Women have access to 24-hour safe spaces; 4) Participatory research
methodologies add valuable knowledge for women experiencing
homelessness; and 5) Service providers be trained in trauma and violence-
informed care.

\section{Introduction}

Homelessness has become a persistent social challenge in developed and developing nations (OECD Affordable Housing Database, 2017; Tipple \& Speak, 2009). Since the 1980s, when mass homelessness in Canada emerged subsequent to a federal divestment in affordable housing, those experiencing homelessness have changed from being a majority of older single men, to a diverse mix including women, families, and youth (Gaetz, Dej, Richter \& Redman, 2016). Although a lack of a permanent, safe, and affordable home is the common factor in

Corresponding author: Amy Van Berkum (amyvanberkum@gmail.com) 
homelessness (Johnson, Gronda \& Coutts, 2008) diverse populations experience homelessness differently. Research has shown that both pathways into and experiences of homelessness are gendered (Thurston, et al., 2013; YWCA Canada, 2016). Homeless women typically experience intersecting challenges including interpersonal violence, poverty, substance use and addiction, poor mental and physical health, and trauma (Haley, Roy, Leclerc, Bourdreau, Bovin, 2004; Hwang, 2001; Van Berkum \& Oudshoorn, 2015). Women's homelessness is typically more hidden and involves insecure or transient housing situations (e.g. abusive relationships, couch surfing) (YWCA Canada, 2013), creating challenges in accurately enumerating homelessness. From recent point in time counts of Canadians utilizing emergency shelter, 35,000 Canadians were homeless on a given night, and approximately 27.3\% were women (Burczycka \& Cotter, 2015; Gaetz et al., 2016). Counts that incorporate sources beyond emergency shelters typically find women make up $35-40 \%$ of homeless populations.

Despite increasing prevalence, the needs of women continue to be under-represented in research literature and in the programs that serve people experiencing homelessness (Canadian Women's Health Network, 2012; Tam, Zlotnick \& Bradley, 2008; YWCA, 2016). Qualitative research illuminates the prevailing theme that women are under-served and experience barriers to system navigation (YWCA Canada, 2016). The need for improved services across government sectors (Gessler \& Maes, 2011; Tam et al., 2008) include gendered considerations (Tedesco, 2013) such as: equitable access; examining service avoidance due to potential child protective services involvement (Tam et al., 2008); addressing women's needs as intersecting and interdependent rather than compartmentalized (Goodman, Fels, \& Glenn, 2006; Miller et al., 2005); reducing service wait times; and altering discriminatory attitudes of service providers (Wen, Hudak, \& Hwang, 2007). Women have specific health care requirements (e.g. illness screening, violence, prenatal care, feminine hygiene), which may have a severe impact on physical, sexual, and mental health (Glesser \& Maes, 2011). Without adequate preventative and primary care services that account for gendered experiences of homelessness, costly visits to acute health care services may ensue (Gessler \& Maes, 2011).

\section{Study objectives}

The purpose of this study is to understand a network of health and social services accessed by women experiencing homelessness, and how individuals navigate these services. The following research questions are addressed: 1) What are women's experiences of accessing homeless-serving and healthcare agencies? 2) What are the gender-based considerations in access to services for women? 3) What are the gaps in services that exist for women, or the opportunities to improve service navigation?

\section{Methods}

\section{Theoretical framework}

This project is guided by critical feminist intersectional theory. Critical Social Theory involves a consideration of societal power and oppression, and opportunities to give space to voices that are historically and currently marginalized (Calhoun, 1995). To this, critical feminist theory adds a focus on gender as a primary location of oppression and an acknowledgement of how patriarchy is intertwined throughout the enactment of both structural and social relations. Lastly, intersectionality theory goes beyond a sole consideration of gender, and includes an understanding of how diverse social locations interact with gender to result in multiple complex layers of oppression (Knudsen, 2006). Therefore, this study focuses on the experiences and empowerment of women, but welcomed discussion of diverse locations of marginalization such as race, ability, sexual orientation, and others. 


\section{Study design}

This study follows a participatory PhotoVoice methodology. Wang and Burris (1994) first introduced PhotoVoice as they studied women's perceptions of health in rural China (Wang, Burris, \& Ping, 1996), grounding PhotoVoice in feminist, constructivism and documentary photography traditions. Essentially, participants of a PhotoVoice study have the opportunity to take photographs related to a community concern. Knowledge of the issue is then generated and advanced as lived experiences are revealed and discussed around the photographs taken (Foster-Fischman, Nowell, Deacon, Nievar, \& McCann, 2005). In the last decade, PhotoVoice has become an increasingly popular qualitative research method, usually employing phenomenology, grounded theory, or participatory action research designs with a priority to create social change (Evans-Agnew \& Rosemberg, 2016; Hergenrather et al., 2009). For populations such as homeless women who may experience marginalization, PhotoVoice is becoming increasingly adopted as a participatory method (Evans-Agnew \& Rosemberg, 2016), with the intent to facilitate partnership and co-learning among participants, researchers, and communities (Fortin, Jackson, Maher, \& Moravac, 2014; Poudrier \& Mac-Lean, 2009; Rhodes \& Benfield, 2006; Walsh, Rutherford, \& Kuzmak, 2010). This project utilized methods of Wang and Burris (1997) adapted to a critical feminist intersectional lens, with arts-informed methods to facilitate participatory dialogue around the photographs (Fortin et al., 2014; Hergenrather et al., 2009). Wang and Burris (1997) stress three essential elements of PhotoVoice methodology: taking and selecting photographs; dialoguing and contextualizing about the meaning in and of the photographs; and coding of issues, themes, or theories.

\section{Data collection}

Ethics approval was obtained from Western University's Research Ethics Board. Participants were recruited from a drop-in centre supporting women experiencing homelessness in a midsized urban centre in Ontario, Canada. Recruitment was conducted through poster advertising and verbal announcements made by agency staff. Participants were required to: communicate in English; provide written consent; be eighteen years of age or older; have the ability to operate a camera; and identify as having lived experience of homelessness. All potential participants were read the letter of information and consent by the Research Coordinator to avoid self-identification of limited literacy. Support for participants was available from staff at the host agency, and participants were provided with a pamphlet of local women's services.

Approximately nine women signed up to participate in the study, with six women ultimately consenting and participating in a series of six sessions. This low participation rate was an anticipated challenge and consistent in literature with similar populations (Baker \& Wang, 2006). In light of this, flexibility and adaptability were incorporated into the research design. For example, women only had to attend one of the first three orientation and discussion sessions to subsequently participate in photograph taking and reflective discussion.

In consultation with staff from the host agency, the research was designed as a six-week artsbased program with the opportunity to complete an individual interview in the two weeks following study completion. Sessions occurred weekly for approximately two hours during fall, 2016. A post-secondary student at the agency was recruited to support the Research Coordinator who was leading data collection. Resources for arts based activities, snacks, and two single-fare bus tickets were provided at each session. Additionally, the four participants who participated in the hour-long independent research interview were provided with a $\$ 20.00$ (CAD) stipend. Ultimately, data was collected by the following means: 1) a demographics questionnaire; 2) key findings and themes field-noted by the Research Coordinator from session discussions; 3 ) the participants' organization of photographs into group-generated themes; 4) participant creative writing; and 5) semi-structured, independent qualitative 
interviews.

Group discussions were facilitated by the Research Coordinator using the mnemonic SHOWED [Table 1], however there was an emphasis on participants directing conversation based on their identified concerns or priorities in an interactive process to teach the researcher about their lives (Ely, Anzul, Friedman, Garner, \& Steinmetz, 1991; Wang, Cash, \& Powers, 2000). This occasionally meant participants engaging in storytelling, which is considered an essence of qualitative research (Reissman, 1993). The Research Coordinator recorded discussion notes, which were later utilized to co-construct themes with the participants.

Table 1: SHOWED Mnemonic (Wang et al., 2000)

What do you See here?

What is really Happening here?

How does this relate to Our lives?

Why does this concern/situation/strength exist?

How can we become Empowered through our new understanding?

What can we Do?

After photographs were developed and shared as a group, the six participants labelled their own photographs with descriptions and organized them on a large display board. Photographs were grouped together collaboratively into themes (Amos, Read, Cobb, \& Pabani, 2012; Fortin et al., 2014). This activity was the first step of the data analysis process in which participants were involved in theme construction (Wang \& Burris, 1997). Creative writing in the form of poetry had not been a pre-determined process, however was included in the qualitative analysis as one participant independently took the initiative to create poetry to append to some of her photographs. Poetry has been utilized in qualitative studies related to health in revealing culture to understand one's community (Furman, 2004) and in creating social justice among groups experiencing poverty and homelessness (Pennebaker \& Seagal, 1999; Wannamaker \& Walsh, 2009).

Finally, one hour qualitative interviews were conducted, also following the SHOWED mnemonic, and focused on the participant's self-selected five favourite photographs. Other questions in the interview guide were related to the gendered experience of accessing services within their community, reasons for service use, barriers and gaps in service provision, collaboration among services, and suggestions for service improvement. Qualitative interviews were audio recorded and transcribed verbatim for data analysis.

\section{Data analysis}

Qualitative descriptive analysis (Guba \& Lincoln, 1985) and Reismann's (1993) narrative analysis are naturalistic, inductive data analysis methods that were used to help make sense of or interpret the variety of data within this study, including group discussion, interviews, creative writing, and photographs. Analysis was completed using NVIVo software to analyse transcribed texts and supplement participant's collaboratively developed themes as a form of triangulation (Golafshani, 2003). Coding was derived inductively from the raw data in an iterative process of critical, self-reflective enquiry related to patterns and themes (MacQueen, McLellan, Kay, \& Milstein, 1998; Mason, 1996). Second level coding was utilized to create categories from these themes (Fotheringham, Walsh, \& Burrowes, 2013). The data were 
reviewed by the Research Coordinator on two separate occasions, before and after memberchecking with participants, to check for coding consistency (Lincoln \& Guba, 1985), re-examine relationships among themes, and test them against the full range of data (Bradley, 1993). The constant comparative method was used (Coleman \& Unrau, 2005) to develop conceptualizations of possible relationships between various sub-sets of data.

\section{Findings}

Participants ranged from 33-57 years old. All participants were Canadian citizens, with five identifying as white and one as Indigenous. Three women identified as being currently housed. For those who were currently experiencing homelessness, two were for a period of 1-6 months and one for 6-12 months. However, all participants indicated multiple experiences of homelessness throughout their lives.

Analysis of the research data followed the three research questions, with two themes generated for each question. For the research question regarding service utilization, themes were: 'On The Margins' and 'Feeling At Home'. For the research question regarding genderbased considerations, themes were: 'Mighty Women' and 'Safety'. For the research question on gaps and opportunities in services, themes were: 'Creating Home' and 'Whatever, Whenever'.

\section{On the margins}

When asked about their experiences of being homeless and requiring support, women shared telling images of an empty, rear bus seat [Figure 1] and a payphone disconnected and dangling below its resting place [Figure 2], which speak to the participants' feelings of being pushed to society's margins. The participants identified how their social locations, such as being a woman, Indigenous, or homeless, contributed to oppression and feeling ostracized from their communities. One participant pointed to a photo she had taken, in which the words First Nation was drawn into the frost of a cold window with her fingertip. The Research Coordinator asked what the photo meant to her, and she responded: "Because we're always fucking forgotten" (Participant 5). A photo of a street sign that read "smart street" was described as a physical representation of the social distancing homeless women feel within their communities. Another photograph of graffiti that read, "ur a weirdo" speaks to the continued overt and covert messaging that contributes to participant's sense of marginalization.

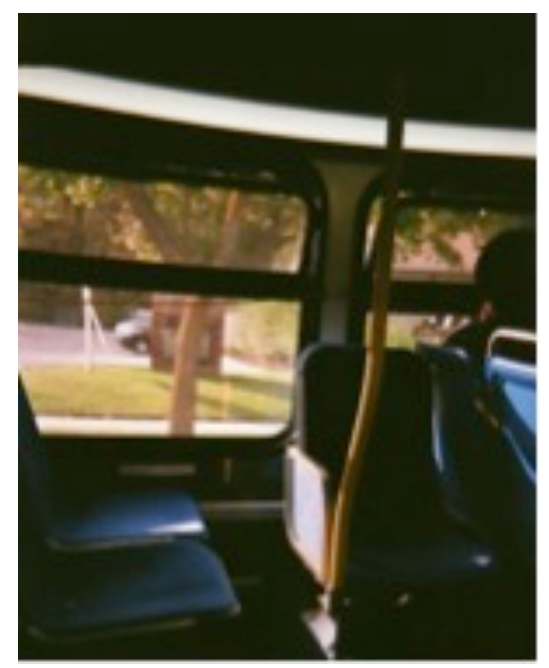

Figure 1: Travelling through life alone 


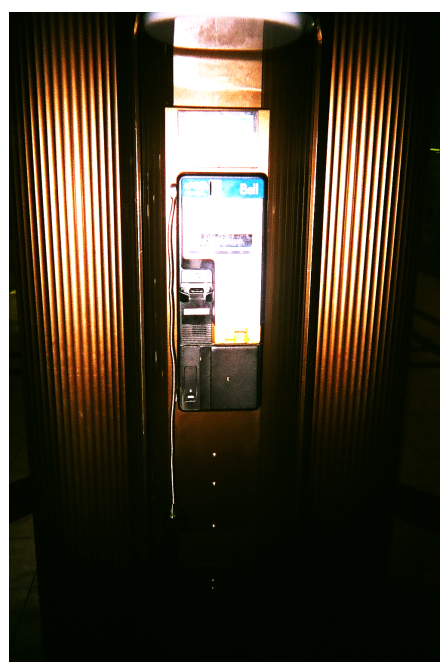

Figure 2: Disconnected- Where will I get help?

Participants also described experiences of transiency, such as couch surfing, as a form of marginalization. Couch surfing was a result of being pushed out of or leaving relationships. Relationship breakdown led to profound feelings of spiritual, emotional, personal, and physical loss. Adopting the sense of being a marginal person, participants dissociated from their sense of self, left damaged relationships with loved ones, were displaced from their homes and personal belongings, and experienced trauma and interpersonal chaos. Being on the margins meant lack of both physical belongings and human connections, with one woman describing homelessness as: "Yeah, so people tryin' to belong to what they got in a garbage bag." (Participant 4)

The women also shared photos and narratives that portrayed haunting examples of marginalization and discrimination. One participant (Participant 6 ) was approached by law enforcement and asked to leave as she attempted to take a picture for this project of a street sign where she described being "sold for sex work." She discussed her experience of being targeted and intentionally went back to the same location and photographed a picture of her outstretched hand to depict the limitations to her personal freedoms in public spaces [Figure 3].

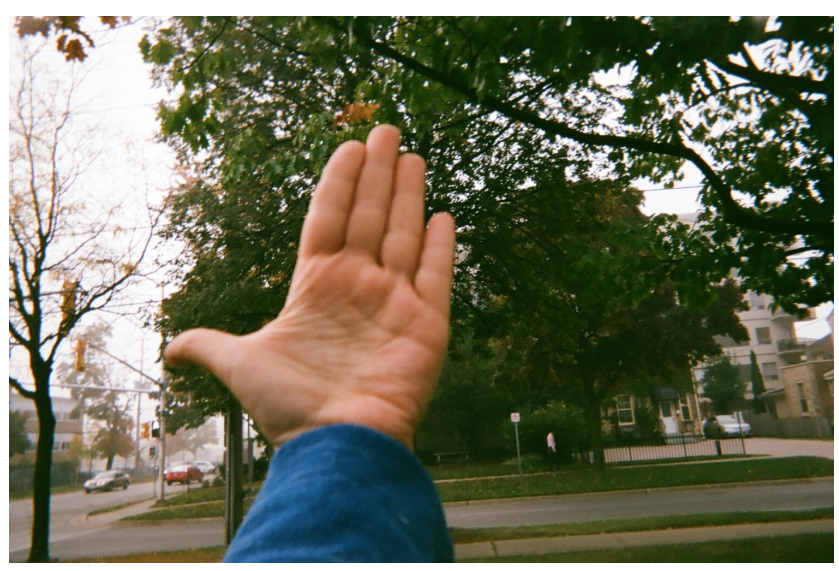

Figure 3: Freedom of expression

Another participant shared a similar thought, identifying how being homeless can involve being 
treated as criminal:

Well you know that they arrest homeless people in public parks and all that, so you know on top of being homeless, then you're double-homeless because you can't even access places that you could crash for the night, so. (Participant 4)

The hand photograph [Figure 3] led to discussion of the varying visibility of women's homelessness, specifically as it related to different populations. For example, participants may feel undesirably and overly visible to law enforcement, perpetrators of violence, or individuals seeking sex. Simultaneously participants spoke to other populations who wished them to be invisible (e.g. middle-high socioeconomic status):

Well um, it's not invisible... there's a despise for it, people despise the homeless. So there's like, a despise, 'how dare he clutter up my street, how dare he bring that issue, it's Christmas, l'm shopping, how dare he show me that ugliness', like, you know? (Participant 4)

The varying degrees of visibility participants experienced, which ranged from feeling targeted to unseen also revealed how one woman desired to more visible and significant in society, summarized with the message depicted in Figure 4 "Something me," and the words of Participant 4 as she described the meaning of this photograph:

Know that I matter, more than anything, yes, crawl your way out of the... but that you're so insignificant that you've left your mark because you're nothing, because you're nobody. And here's my mark. I am significant. (Participant 4)

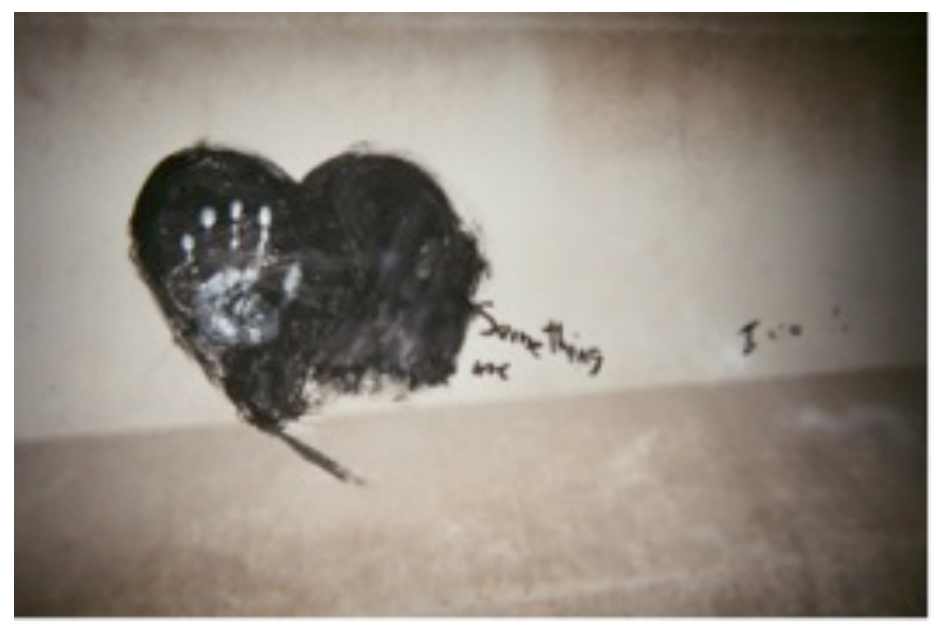

Figure 4: Something me

Participants described the marginalization they experienced through rules and policies targeted to individuals experiencing homelessness. This included rules about loitering in public venues [Figure 5] and social services policies to lock doors [Figure 6]. 

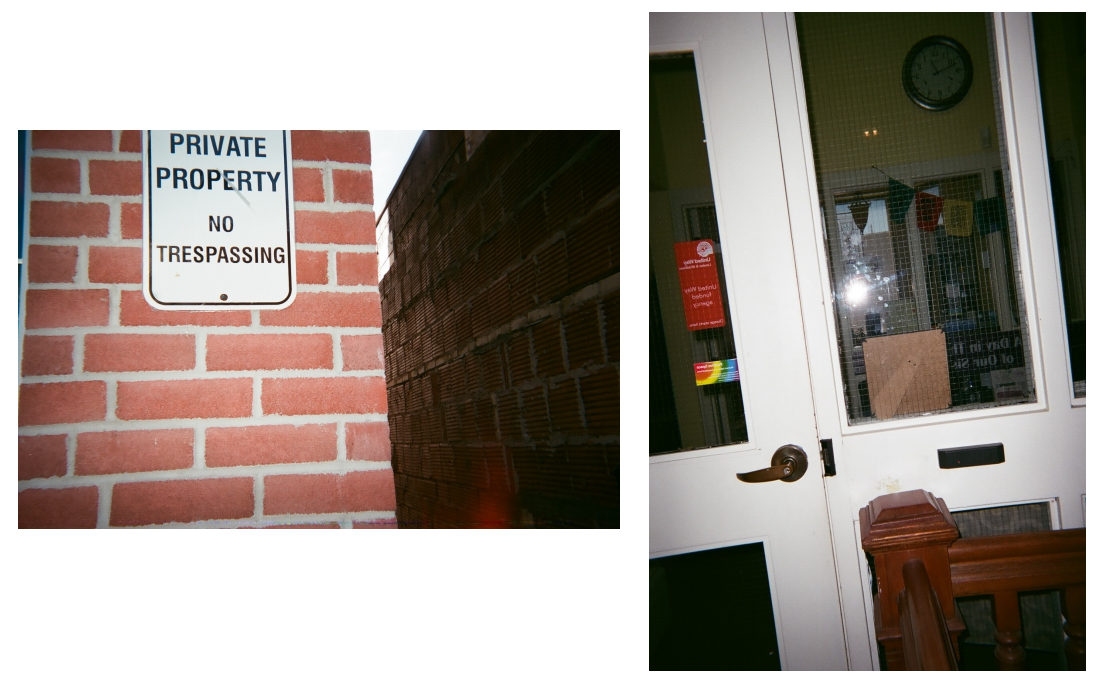

Figure 5: Barriers

Figure 6: Locked doors

\section{Feeling at home}

Conversely, participants also shared positive experiences of seeking support while experiencing homelessness. Throughout group sessions and individual interviews, participants listed several characteristics of agencies that they felt pulled them in from the margins, including: a welcoming atmosphere; safety; building relationships with others; feeling comfortable and at home; free access to basic needs; drop in style programs and activities; on-site supports and workers; and a low threshold for access combined with clear rules around access to resources (e.g. internet, phone, washrooms, laundry). Service providers were identified as playing a significant role in this positive service experience [Figure 7]. Figure 7 was taken in a local women's drop in centre, where participants commonly shared communicating and connecting with service workers over community meals. During group sessions, participants identified the following characteristics of service providers: making exceptions to rules; being kind; possessing strong leadership skills; being helpful; not highlighting power differentials; being aware and conscientious of creating and facilitating a safe environment; being friendly and engaged in conversation; providing timely responses; being non-judgmental; and providing suggestions and information.

We've all kind of become one huge collective family, so the staff like, you know, they don't particularly like to be called staff because they don't want to put themselves above other people. (Participant 2) 


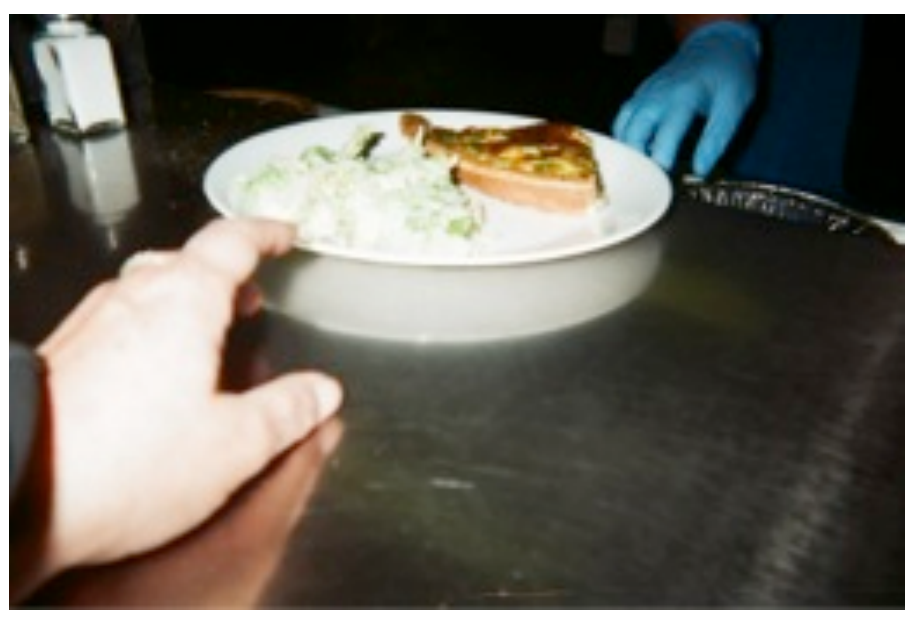

Figure 7: Hungry - you feed me, provide hospitality and a safe gathering

\section{Mighty women}

When discussing the experience of being a woman and on the margins of society, participants focused on how women, including themselves, are mighty advocates for social justice. Participants challenged the current state of their city, sharing a photograph of a derelict alleyway between run down concrete buildings. In deciding the title for the image, the women played on the nickname for their community and asked, "Is this our forest city?" Participants challenged societal values and the disparity across social classes:

It's almost to the point where it's a human rights violation, almost to the point where we're being used for [the upper classes] to keep their social status and jobs. (Participant 1)

As participants identified the disparities within the status quo, they reflected on the important role of women in families, and subsequent generational impacts. Participants shared photographs [Figure 8] of tiny handprints that trailed off on cobbled stone and reflected on the impact of intergenerational poverty and how it erodes innocence. The participants shared a common discomfort with not knowing what the future holds for people of all genders, but a passion for making it better.

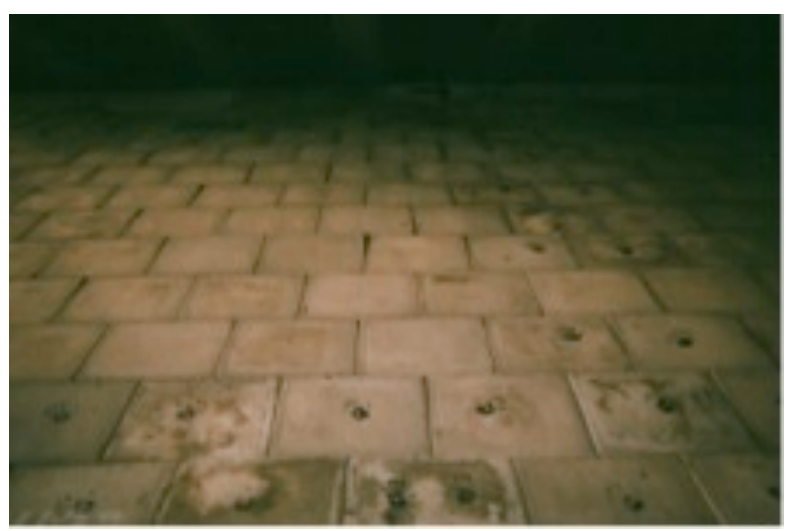

Figure 8: Innocence once forgotten. What does the future hold for the lives of the innocent, our children? 
Participants shared their strengths as women as they engaged in future directed thinking. They highlighted the value of hope, including a photograph of a metal ladder under a bridge leading up to an area where homeless individuals often sleep. The photograph [Figure 9] was labelled: "Once you hit the bottom, the only way left is up (Participant 1)." Another photograph of a local church that runs several services for marginalized individuals was given the title of: "I lift my eyes up, where does my help come from (Participant 2)", and was described as encompassing a sense of optimism. Participants shared feelings of empowerment, agency, and hope as they discussed issues and opportunities to be strong leaders of change.

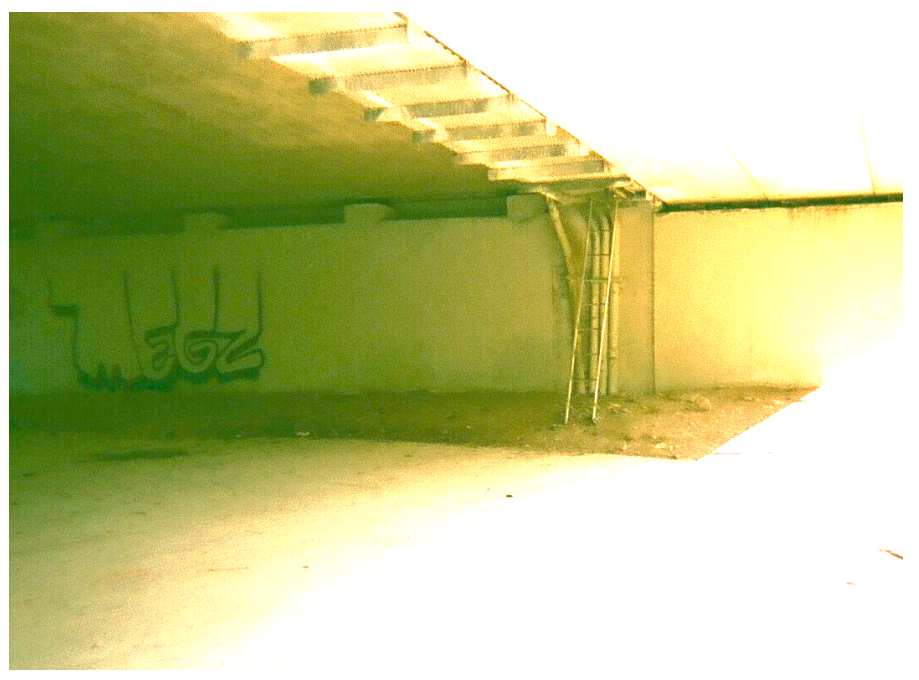

Figure 9: Once you hit the bottom, the only way left is up.

\section{Safety}

While women identified themselves as mighty and empowered to create change, they also identified that women who are homeless experience constant threats to safety. These can include explicit physical threats, but also limitations in services that place them at potential risk. In particular, where gaps in social services were identified, compromised safety was highlighted. In the community of study, there are very few shelter beds for women, and apart from violence against women (VAW) shelter beds, these are in mixed settings with men. Additionally, the women expressed concern that there are no 24-hour women's only drop-in services, and that crises and risks to safety happen at all hours of the day and night. The impacts of these gaps were highlighted explicitly:

It would be a lot safer for women to be in some place like [name of daytime drop in shelter], not out on the street where they're getting raped or they have to sell themselves for a place to sleep. They shouldn't have to do that. They need a safe place for those hours that aren't covered. Especially for women because women shouldn't be on the streets. (Participant 1)

Again and again in group sessions the ongoing fear for homeless women was compromised safety within their communities. Participants shared personal experiences of violence, discrimination, and an uncertainty about whether or not they could rely on current social structures to help keep them safe (e.g. law enforcement, shelters, health services). Any step to access support services might actually put a woman at risk: calling police might lead to 
increased violence from a partner; moving into housing with a male roommate might lead to sexual violence; staying in shelter might lead to being robbed. One participant describes the tension of trying to make housing affordable by finding a roommate:

And it turns out the only person who answered the ad was this guy and I'm thinking, I don't know if I want to live and share my house with some guy I don't know. Because you know, you worry about stuff like, is he abusive will he start smacking me around or whatever. What if he tries to sexually assault me or something, right? So I was really scared. (Participant 3)

The role of gender revealed itself many times as services were discussed. Participants questioned why there were men-only emergency shelters, and not women-only shelters. Participants debated the ideal gender of staff in services and ultimately concluded that there should be services with: female-only staff, male-only staff, and services with staff of diverse genders. The variance in women's perceptions reinforces the need for variety in service models.

\section{Creating home}

Reflecting on gaps in services or opportunities for improvement, participants continually circled back to their lack of safe, affordable, adequate, accessible and permanent housing. During solution-focused discussions, participants identified positive characteristics of home and the necessity to improve housing. Participants revealed barriers to housing as they shared experiences of homelessness and eviction, long wait lists for social housing, unaffordable rents, labour intensive application processes, and unsafe and unhealthy conditions:

You know, months and months and months uh, my husband had applied for like, fifteen years ago, and you know, they called him back ten years later and said, 'we have a house for you now. (Participant 2)

The impact of inadequate housing for women can mean making constrained choices coupled with risk. One participant described fear of their roommate. Another participant shared:

A lot of women will sell themselves just to get a place to stay. (Participant 1)

Participants identified that there are important factors required to help improve situations of homelessness for women. Being adequately supported in finding and maintaining housing was discussed, as women shared how shelter exit deadlines in addition to insufficient housing stability support, particularly around mental health and substance use, can lead to repeated homelessness. Participant 2 shared her experience of a service that supported her mental health stability:

[Organization] was able to provide, you know, services that I needed there to help control my mental health...you know like, my brain is stable, I can look for housing or I can look for this or I can look for that. (Participant 2)

Women consistently shared the need for appropriate supports and a primary worker, ideally to help with complex system navigation. Participants all reflected on times in their lives when they asked, "How do I become housed?" Financial assistance in both becoming housed and remaining housed is essential. When participants reflected on positive characteristics of home, they shared: feeling safe, healthy relationships, controlled rents, and the ability to create home within their house [Figure 10]. Participants engaged actively in solution-driven thinking, sharing ideas about triaging housing for high-risk women, lowering market rents to divert people from social housing wait lists, and revitalizing unused buildings to create permanent housing for 
those experiencing homelessness. One woman reflected on a photograph [Figure 11] of a former hospital no longer occupied:

Like it's a waste of space. Here you have a perfectly good building, I'm sure everything's fine. l'm sure it may need some repairs because it may be old, I don't know what the inside looks like, but when I see people sleeping on the sidewalk or I see people sleeping in a doorway, and then I see this, that infuriates me. (Participant 1)

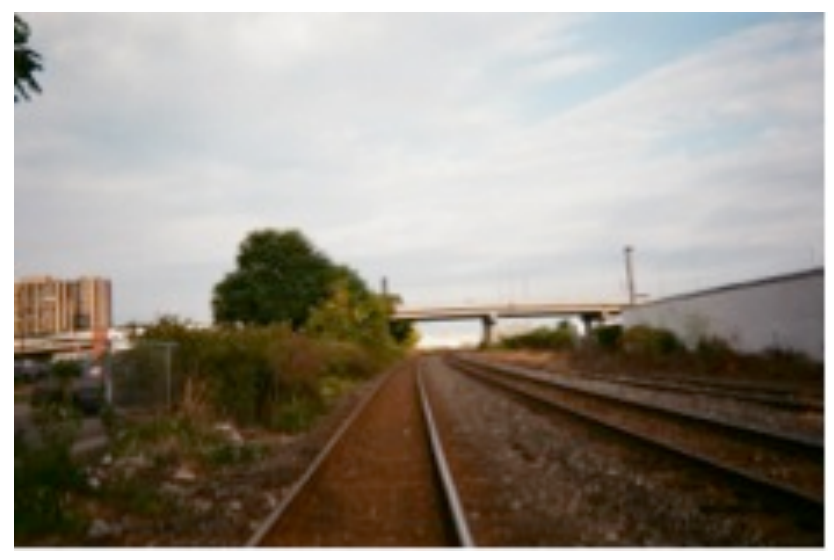

Figure 10: Where to now?

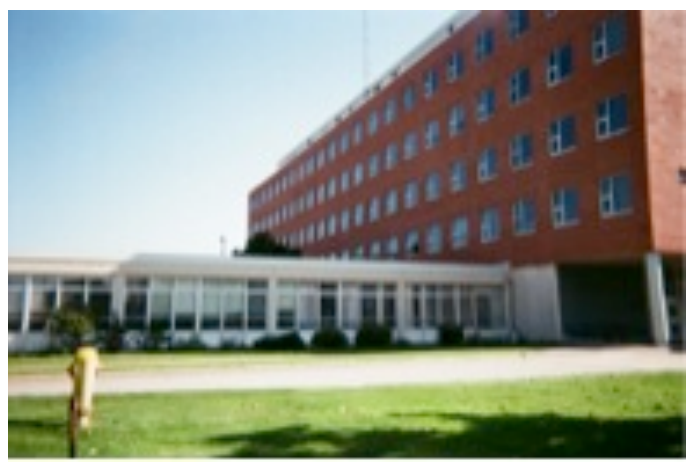

Figure 11: Wasted space

\section{Whenever, wherever}

When asked to reflect on how services could be refined to better meet their needs, participants expressed that they felt as though the community had a broad landscape of services. Participants agreed however, that services were under-funded, which led to gaps and inaccessibility in service provision such as physical location, and limited hours and resources (e.g. transportation, long wait lists, untimely access to staff, basic needs provision):

There should be a place offered for women during [all] hours. And that's important. That's something that I don't see anybody [doing]. They have it in Montreal, they have up to a certain time, about 1:00, 1:30 in the morning you can go there and have coffee, you can talk to a worker. But we don't have 
anything like that here. At night. (Participant 1)

But that, that time period is not covered [by harm reduction outreach] and that's when it's needed the most. How many people think, oh l'm going to need a needle at 2, 3 in the morning? They're using dirty needles. (Participant 1)

While expressing that services for homeless men were very important and similar in ways, participants highlighted that women's shelters were limited, especially for those who are not currently leaving intimate partner violence:

If you needed to provide shelters for the women, there shouldn't be, like, specific types of shelters all like, 'Oh, we'll provide shelter for you, but only if you've been in an abusive relationship' and things like that, you know? (Participant 4)

In the [name of shelter], they have three floors for the men, they have one half floor for the women, and the other half of that same floor is for people who are trying to get off drugs. If the shelters are full, there's no other options, you're out on the street [Figure 12]. (Participant 1)

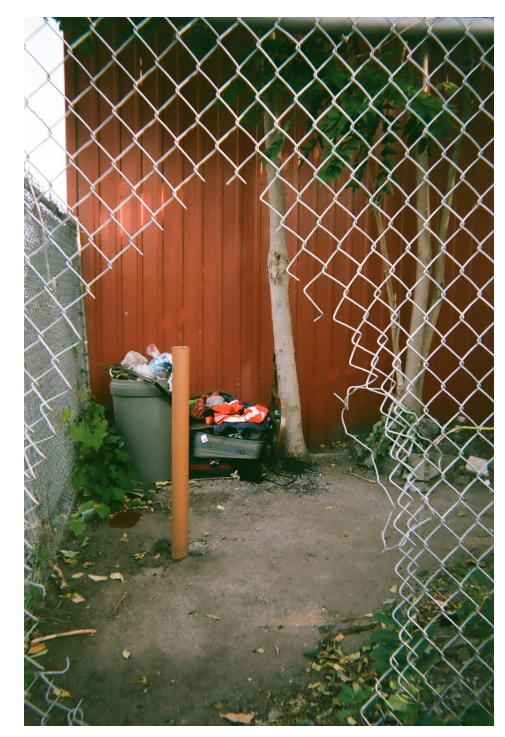

Figure 12: Life on the Streets

Participants also described restrictive service provision and rigid criteria, which meant that services felt exclusive rather than inclusive. For example, participants described: having to have a family doctor or children to access services; age or gender restrictions; shelter rules that restrict access to those who use substances; requirement of a home address to apply for social assistance; and limitations to the number of times services can be accessed (e.g. food bank).

But then [they] say something like, you know, 'Until you're drug free, we can't help you,' but then they don't offer places you can go to get help for your addiction and stuff. So it was like, you know, I really want to work. (Participant 2)

Furthermore, participants identified a lack of awareness about which services are available and apprehension about accessing some services due to uncertainty, violence, substance use, theft, and negative experiences with service providers. Participants typically learned about services through word of mouth or accidental discovery. Within services, participants described 
experiences of feeling censored, stigmatized, and dismissed:

Locked doors symbolizes that, you know, help or whatever they need is kinda out of reach, you know? So, so lock people out of services, I mean, that's not cool. (Participant 2)

Overall, participants wanted to see barriers to access eliminated.

\section{Discussion}

As each week of the six week program passed, the participant's anger and frustration with inadequacy of systems grew. Women shared narratives of systemic oppression that in some ways disconnected them from their surroundings, while in others, wove them together in shared understandings. It was these shared understandings that participants drew upon as they consolidated their photographs and organized them into themes. The photographs were adhered to a display board [Figure 13] and the connections between the photographs, themes, and participants themselves became visible. In the middle of the board participants posted a "Homeless Charter of Rights" that was obtained from the Internet. The Charter of Rights indicates that everyone experiencing homelessness should be treated with dignity and respect, and has the ability to exercise their human rights.

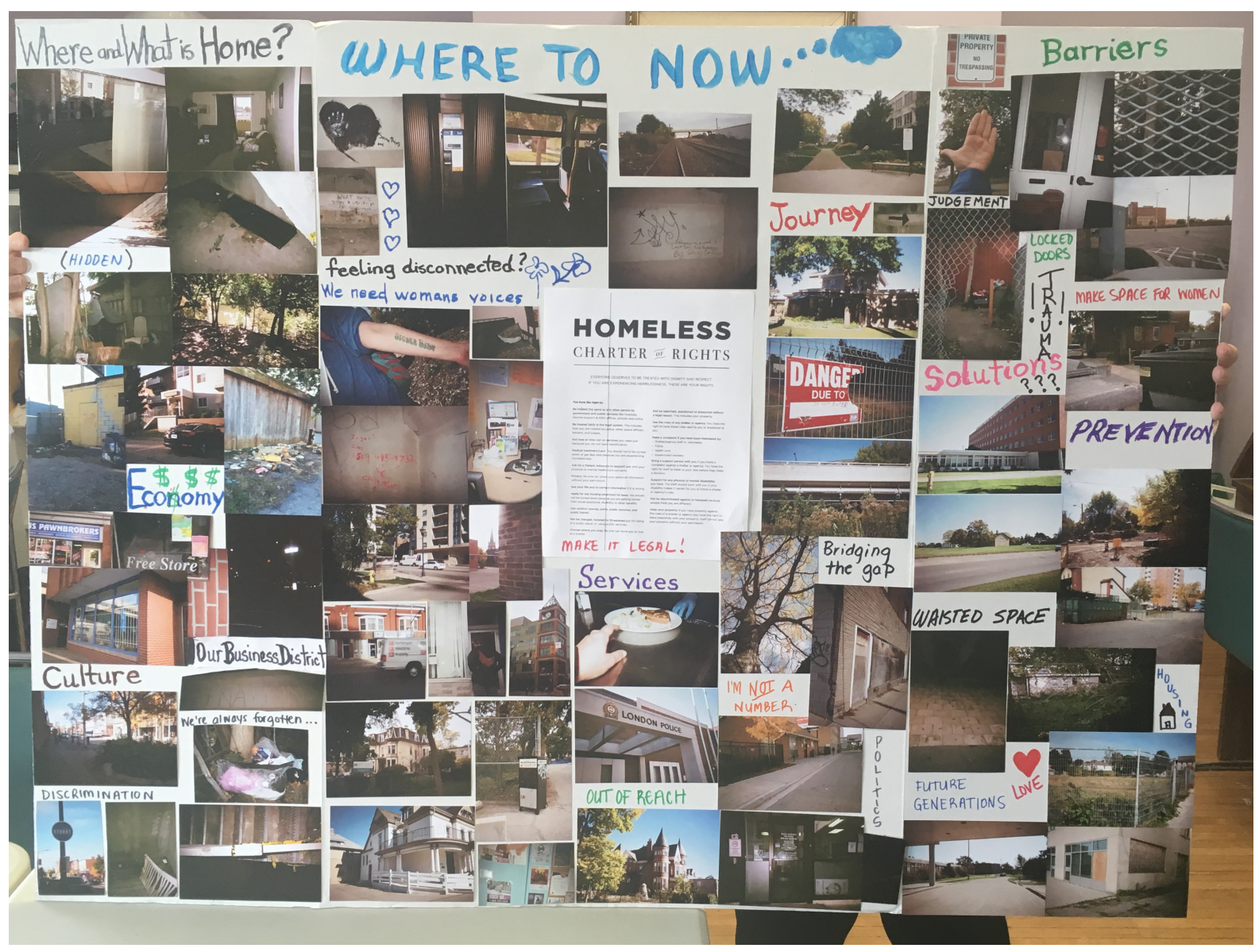

Figure 13: Participants thematic display board

While much of the discussion was rooted in frustration, participants also spoke to and demonstrated their strengths and agency for change. While the photographs, themes, and 
accompanying descriptions have been displayed outside a large public library, in a drop-in space for women experiencing homelessness, and at a national conference on homelessness. At the time of writing the women are seeking further venues in which to share and display their stories to bring awareness to the issue of women's homelessness and to advocate for change.

The findings demonstrate an important tension between marginalization and empowerment. While participants identified how systems were disconnected, inaccessible, or discriminatory, leading to poor health and social outcomes, they also identified as mighty, empowered, and united. This provides a valuable caution to those trying to frame the experience of women's homelessness, with a sole focus on vulnerabilities and negative outcomes potentially serving to further disempower women, while a sole focus on resilience might negate the structural violence inherent in current systems and services. This is why the PhotoVoice participatory method, grounded in a critical feminist intersectional lens, was a valuable process in ensuring the complexities of women's experiences were captured. This participatory process can itself be crucially empowering to those chronically excluded, as highlighted by the YWCA (2016, p. 6 ), "Homelessness is not only a material state; it is a social category whose members are systematically excluded from decision-making."

Participants and the research team collaboratively developed five practical recommendations from their reflections: 1) Lack of housing continues to be a key factor underlying the harmful experience of homelessness, and more safe, supported, permanent, and affordable housing is required as a foundation for exiting homelessness; 2) Any new government resources or programs to end homelessness must account for the unique experiences and needs of women, ideally inclusion of both targeted resources and a general gender lens; 3) Because of the high risk for experiencing violence and other traumatic encounters, women need access to 24-hour safe spaces that also ground them in access to housing; 4) Participatory research methodologies should be prioritized for women experiencing homelessness so that research is a process of empowerment; and 5) All service providers (e.g. justice, education, health) who come in contact with women experiencing homelessness should be trained in trauma and violence-informed care.

\section{Limitations}

Initial recruitment and subsequent retention was difficult, where many women were enthusiastic to sign-up, but either did not subsequently show, or left the drop-in space as the group commenced. The need for consistency of participants to develop the analysis of the photographs over time meant that the project recruited a sub-set of six women in more stable situations. In particular, only three of the six participants were in current experiences of homelessness, a proportion not reflective of the population generally accessing the drop-in space. However, as all the participants had lived experiences of homelessness, their insights are conceivably congruent with the population of concern. Recruiting women through a social service agency may also have excluded unique experiences of those women who do not access such services. Lastly, although there has been collaborative dissemination of findings with participants in public venues, opportunities for dissemination and policy advocacy are still being pursued.

\section{Conclusion}

Active involvement of people with lived experience of homelessness is a rights based approach to developing research knowledge and change (United Nations, 2015; YWCA, 2016). This PhotoVoice study explored women's experiences of accessing homeless-serving and healthcare agencies, how gender influences these experiences, and both gaps and opportunities in existing services. It was clear that while women are searching for home, safety, and more timely access to services, they also co-created the feeling of being at home, found 
ways to empower themselves, and pushed back from societal margins. While being homeless was rooted in trauma and was traumatic in-and-of itself, study participants desired to be change agents, sharing their stories with the community and influencing policy-makers. Ultimately, services must meet the unique needs of women and provide a platform for women to be agents of change in their own lives and communities.

\section{References}

Amos, S., Reed, K., Coob, M., \& Pabani, N. (2012). Facilitating a photovoice project: What you need to know. The Nova Scotia participatory food costing project of the Nova Scotia food security network. Retrieved from https://foodarc.ca/makefoodmatter/wp content/uploads/sites/3/VOICES_PhotovoiceManual.pdf

Baker, T. A., \& Wang, C. C. (2006). Photovoice: Use of a participatory action research method to explore the chronic pain experience in older adults. Qualitative Health Research,16(10), 1405-1413. doi:10.1177/1049732306294118

Bradley, J. (1993). Methodological issues and practices in qualitative research. The Library Quarterly: Information, Community, Policy, 63(4), 431-449. doi:10.1086/602620

Burczycka, M., \& Cotter, A. (2010). Shelters for abused women in Canada, 2010. Retrieved from http://www.statcan.gc.ca/pub/85-002-x/2011001/article/11495-eng.pdf

Calhoun, C. (1995). Critical social theory: Culture, history, and the challenge of difference. Cambridge, MA: Wiley-Blackwell.

Canadian Women's Health Network. (2012). Women, housing, and health. Retrieved from http://www.cwhn.ca/en/resources/primers/housing

Coleman, H., \& Unrau, Y. (2005). Analyzing qualitative data. In R. M. Grinnell, \& Y. A. Unrau (Eds.), Social work research and evaluation: Qualitative and quantitative approaches ( $7^{\text {th }}$ ed., pp. 88-119). New York: Oxford University Press.

Ely, M., Anzul, M., Friedman, T., Garner, D., \& Steinmetz, A. M. (1991). Doing qualitative research: Circles within circles. London: Falmer Press.

Evans-Agnew, R. A., \& Rosemberg, M. S. (2016). Questioning photovoice research. Qualitative

Health Research, 26(8), 1019-1030. doi:10.1177/1049732315624223

Fortin, R., Jackson, S., Maher, J., \& Moravac, C. (2014). I WAS HERE: Young mothers who have experienced homelessness use photovoice and participatory qualitative analysis to demonstrate strengths and assets. Global Health Promotion, 22(1), 8-20. doi: $10.1177 / 1757975914528960$

Foster-Fishman, P., Nowell, B., Deacon, Z., Nievar, M. A., \& McCann, P. (2005). Using methods that matter: The impact of reflection, dialogue, and voice. American Journal of Community Psychology, 36(3), 275-291. doi:10.1007/s10464-005-8626-y

Fotheringham, S., Walsh, C. A., \& Burrowes, A. (2014). "A place to rest": The role of transitional housing in ending homelessness for women in Calgary, Canada. Gender, Place \& Culture, 21(7), 834-853. http://doi.org/10.1080/0966369X.2013.810605

Furman, R. (2004). Using poetry and narrative as qualitative data: Exploring a father's cancer through poetry. Families, Systems \& Health, 22(2), 162-170. doi:10.1037/10917527.22.2.162

Gaetz, S., Dej, E., Richter, T., \& Redman, M. (2016). The state of homelessness in Canada $2016 . \quad$ Retrieved from http://homelesshub.ca/sites/default/files/SOHC16_final_200ct2016.pdf

Gessler, S., \& Maes, C. (2011). The Winnipeg street health report. Retrieved from http://homelesshub.ca/sites/default/files/Wpg.St.Health.Report.2011.pdf

Golafshani, N. (2003). The qualitative report understanding reliability and validity in qualitative research understanding reliability and validity in qualitative research. The Qualitative Report, 8(4), 597-606. Retrieved from http://nsuworks.nova.edu/tqr

Goodman, L., Fels, K., \& Glenn, C. (2006). No safe place: Sexual assault in the lives of 
homeless

women.

Retrieved

from

https://vawnet.org/sites/default/files/materials/files/2016-

09/AR_SAHomelessness.pdf

Haley, N., Roy, E., Leclerc, P., Boudreau, J.-F., \& Boivin, J.-F. (2004). Characteristics of adolescent street youth with a history of pregnancy. Journal of Pediatric and Adolescent Gynecology, 17(5), 313-320. http://doi.org/10.1016/j.jpag.2004.06.006

Hergenrather, K. C., Rhodes, S. D., Cowan, C. A., Bardhoshi, G., \& Pula, S. (2009). Photovoice as community-based participatory research: A qualitative review. American Journal of Health Behavior, 33(6), 686.

Hwang, S. (2001). Homelessness and health. CMAJ, 164(1), 229-233. Retrieved from http://www.cmaj.ca/content/cmaj/164/2/229.full.pdf

Johnson, G., Gronda, H., \& Coutts, S. (2008). On the outside: Pathways in and out of homelessness. Melbourne Australia: Vic. Australian Scholarly Publishing. Retrieved from https://trove.nla.gov.au/work/35327083?selectedversion=NBD43147420

Knudsen, S. V. (2006).Intersectionality - A theoretical inspiration in the analysis of minority cultures and identities in textbooks. In E. Bruillard, B. Aamotsbakken, S. V.

Knudsen, \& M. Horsley (Eds.), Caught in the Web or Lost in the Textbook? (pp. 61-76). Paris: Jouve, Thousand Oaks, CA: Sage.

Lincoln, Y. S., \& Guba, E. G. (1985). Naturalistic Inquiry. Newbury Park, CA: Sage Publications.

MacQueen, K. M., McLellan, E., Kay, K., \& Milstein, B. (1998). Codebook development for team-based qualitative analysis. Field Methods, 10(2), 31-36. doi:10.1177/1525822X980100020301

Mason, J. (1996). Qualitative Researching. London: Sage.

Miller, M. D., Hodgkins, C. C., Touchton, R., Estlund, K. L., Garces, L., \& Christensen, R. C. (2005). Homeless, mentally ill and addicted: The need for abuse and trauma services. Journal of Health Care for the Poor and Underserved, 16(4), 615-622.

OECD Social Policy Division- Directorate of Employment, L. and S. A. (2017). HC3.1 Homeless Population. Retrieved from https://www.oecd.org/els/family/HC3-1-Homelesspopulation.pdf

Pennebaker, J. W., \& Seagal, J. D. (1999). Forming a story: The health benefits of narrative Journal of Clinical Psychology, 55(10), 1243-1254. doi:10.1002/(SICI)1097 4679(199910)55:10<1243::AID-JCLP6>3.0.CO;2-N

Poudrier, J., \& Mac-Lean, R. T. (2009). "We've fallen into the cracks:" Aboriginal women's experiences with breast cancer through photovoice. Nursing Inquiry, 16, 306-317. doi: 10.1111/j.1440-1800.2008.00432.x

Rhodes, S. D., \& Benfield, D. (2006). Community-based participatory research: An introduction for the clinician researcher. In J. D. Blessing (ed.), Physician assistant's guide to research and medical literature $\left(2^{\text {nd }}\right.$ ed., pp. 105-118). Philadelphia, PA: F. A. Davis.

Riessman, C. K. (1993). Narrative analysis. Qualitative Research Methods Series, No. 30. Newbury Park, CA: Sage.

Tam, T., Zlotnick, C., \& Bradley, K. (2008). The link between homeless women's mental health and service system use. Psychiatric Services, 59(9), 1004-1010. Retrieved from https://media-proquest-

com.proxy1.lib.uwo.ca/media/pq/classic/doc/1556857241/fmt/pi/rep/NONE?cit\%3Aa uth $=$ Tam $\% 2 \mathrm{C}+$ Tammy+W\%2C+PhD\%3BZlotnick\%2C+Cheryl $\% 2 \mathrm{C}+\mathrm{RN} \% 2 \mathrm{C}+\mathrm{DrPH}$ $\% 3 \mathrm{BBradley} \% 2 \mathrm{C}+$ Kimberly $\% 2 \mathrm{C}+\mathrm{PsyD}$ \&cit\%3Atitle=The+Link+Between+Homeless + Women $\% 27 \mathrm{~s}+$ Mental+Health+an

Tedesco, G. (2013). Housing in Hamilton: Promoting safe, affordable, healthy housing for all raise the hammer. Retrieved from https://www.raisethehammer.org/article/2014/?view=nested

Thurston, W. E., Roy, A., Clow, B., Este, D., Gordey, T., Haworth-Brockman, M., ... Carruthers, L. (2013). Pathways into and out of homelessness: Domestic violence and housing security for immigrant women. Journal of Immigrant \& Refugee Studies, 11(3), 278- 
298. http://doi.org/10.1080/15562948.2013.801734

Tipple, G., \& Speak, S. (2009). The hidden millions [electronic resource]: Homelessness in developing countries / Graham Tipple and Suzanne Speak. - Version details - Trove. (G. Tipple \& S. Speak, Eds.). London; New York : Routledge . Retrieved from https://trove.nla.gov.au/work/25746314?selectedversion=NBD46296594

United Nations. (2015). United Nations General Assembly report of the special rapporteur on adequate housing as a component of the right to an adequate standard of living, and on the right to non-discrimination in this context (UN report $\mathrm{A} / \mathrm{HRC} / 31 / 54)$. Retrieved fromhttp://www.ohchr.org/EN/HRBodies/HRC/RegularSessions/Session31/Pages/Li stReports.apx

Van Berkum, A., \& Oudshoorn, A. (2015). Best practice guideline for ending women's and girl's homelessness. Retrieved from http://ywcacanada.ca/data/research_docs/00000347.pdf

Walsh, C. A., Rutherford, G., \& Kuzmak, N. (2010). Engaging women who are homeless in community-based research using emerging qualitative data collection techniques. International Journal of Multiple Research Approaches, 4(3), 192-205. doi:10.5172/mra.2010.4.3.192

Wang, C. C., \& Burris, M. A. (1997). Photovoice: Concept, methodology, and use for participatory needs assessment. Health Education and Behaviour, 24(3), 369-387. doi:10.1177/109019819702400309

Wang, C. C., Burris, M. A. \& Ping, X. Y. (1996). Chinese village women as visual anthropologists: A participatory approach to reaching policymakers. Social Science \& Medicine, 42, 1391-1400. doi:10.1016/0277-9536(95)00287-1

Wang, C. C., Cash, J. L., \& Powers, L. S. (2000). Who knows the streets as well as the homeless? Promoting personal and community action through photovoice. Health Promotion Practice, 1(1), 81-89. http://doi.org/10.1177/152483990000100113

Wannamaker, C., \& Walsh, C. A. (2009). Raising consciousness about homelessness and poverty through poetry. Canadian Social Work, 11(1), 60-76.

Wen, C. K., Hudak, P. L., \& Hwang, S. W. (2007). Homeless people's perceptions of welcomeness and unwelcomeness in healthcare encounters. Journal of General Internal Medicine, 22(7), 1011-7. http://doi.org/10.1007/s11606-007-0183-7

YWCA Canada. (2013). Housing first, women second? A brief from the homes for women campaign. Retrieved from http://ywcacanada.ca/data/documents/00000382.pd

YWCA Canada. (2016). Counting women and girls into the national housing strategy. Retrieved from http://ywcacanada.ca/data/publications/00000088.pdf

\section{Biographical Notes}

Amy Van Berkum is a Registered Nurse and PhD student with interest in homelessness, social justice, trauma informed care, health equity, and health promotion. Amy's work experience spans a variety of health care and academic roles.

Abe Oudshoorn is an Assistant Professor in the Arthur Labatt Family School of Nursing and Department of Psychiatry, Schulich School of Medicine and Dentistry. His research covers issues of mental health, gender, housing loss, homelessness prevention, and health equity. 